\title{
Problems and Countermeasures of News Communication Education in Local Colleges and Universities
}

\author{
Xiaojuan Zhao ${ }^{1 *}$ \\ ${ }^{1}$ School of Humanities, Weinan Normal University, Weinan, Shaanxi, 714099, China \\ *Corresponding author. Email: myresearch2021@163.com
}

\begin{abstract}
Under the background that the innovation of media technology has brought great changes to the media ecological environment, the traditional educational idea and teaching mode of news communication have been difficult to meet the requirements of the media talents training in the age of intelligent media. This paper puts forward the countermeasures to solve the problems existing in the education of news communication in local colleges and universities, which should reform from renewing ideas, improving teachers, reforming teaching system and perfecting talent training programs.
\end{abstract}

Keywords: Intelligent media, education of news communication, countermeasures

\section{地方高校新闻传播教育 面临的问题与对策}

\author{
作者：赵晓娟 ${ }^{1 *}$ \\ ${ }^{1}$ 单位: 渭南师范学院人文学院, 渭南, 陕西, 中国, 714099 \\ *通讯作者e-mail: myresearch2021@163.com \\ 摘要: \\ 媒体技术的革新为媒介生态环境带来了巨大的变化,传统的新闻传播教育理念和教学模式已经很难适应智媒体 \\ 时代媒介人才培养的要求。本文针对地方高校新闻传播教育存在的问题，提出应该从更新观念、改善师资、改 \\ 革教学体系、完善人才培养方案等方面进行改革的对策。
}

关键词: 智媒体; 新闻传播教育; 对策

\section{1. 我国高校新闻传播教育的发展背景}

随着 $5 \mathrm{G}$ 移动通信、大数据、云计算、人工智能等 技术的不断发展，新闻传媒行业发生了巨大的变化， 从而催生了智能媒体时代的到来。媒体融合的大环境 使得信息传播模式和人们的社交方式发生了巨大变 化。中国互联网络信息中心 (CNNIC) 发布的第46次 《中国互联网络发展状况统计报告》显示, 截至2020 年6月, 我国网民规模达 9.40 亿, 互联网普及率达 $67.0 \%$ 。[1] 互联网和手机终端已经成为信息传播的主 要途径。媒介生态结构已然发生了根本性变化, 以三
微一端为代表的新型媒体兴起, 传统媒体向新型媒体 融合转型。融媒体技术集成了影像、声音、文字为一 体，网站、论坛、QQ、博客、微博、微信、短视频平 台、直播平台等诸多网络新媒体平台已经成为社会信 息传播的重要形式。教育部、中共中央宣传部发布《关 于提高高校新闻传播人才培养能力实施卓越新闻传 播人才教育培养计划 2.0 的意见》, 提出全面落实立 德树人根本任务, 坚持马克思主义新闻观, 用中国特 色社会主义新闻理论教书育人, 培养造就一大批具有 家国情怀、国际视野的高素质全媒化复合型专家型新 闻传播后备人才。[2]为了适应新闻传媒行业人才需 
求的变化, 新闻传播类专业人才培养应该符合融媒体 发展的需要, 培养复合型专业人才。人才培养的目标 应该随着行业变化与时俱进, 不断革新, 运用全新的 理念和技术改进教学活动。

截至2017年，全国有681所高校开设新闻传播类 专业，本科专业点 1244 个，其中新闻 326 个，广播电 视 234 个, 广告 378 个, 传播学 71 个, 编辑出版 82 个, 网络与新媒体 140 个, 数字出版 13 个, 在校本科生有 23 万人，在校教师 7000 人。[3]以陕西为例，2000年 以前, 只有西北大学和陕西师范大学办有新闻专业。 现如今, 西安外国语学院、西北政法学院、西安交通 大学、长安大学、延安大学、长安大学、西安工业大 学等多所大学都相继开办了新闻传播类专业, 民办教 育也迅速介入新闻传播教育, 西京学院、西安欧亚学 院、西安外事学院、西安培华学院等院校设立的新闻 传播类专业已初具规模。2003年渭南师范学院也正式 步入了高等新闻院校的行列, 2003年开设广播电视新 闻学专业, 2005 年又增设了新闻学专业, 后来又陆 续开办了广告学、广播电视编导、数字媒体艺术、网 络与新媒体等专业。

\section{2. 地方高校新闻传播教育面临的问题}

新闻传播教育的快速超常规发展, 必然存在着许 多令人困扰的问题。高校新闻传播教育不仅存在高校 扩招后新出现的普遍问题, 更有许多长期形成的问题 严重影响到教育的质量和发展。专业规模的高速扩 容, 专业设置标准的降低, 导致校际间的低水平竞争 加速, 人才培养质量大幅度下降。[3]因此, 我们有 必要寻找问题, 谋求新闻传播教育的良性发展。

\section{1. 师资力量不足，师生比例失调}

随着专业招生规模扩大, 学生数量猛增, 教师人 数、学历层次没有得到相应的提高, 师生比例走高, 部分学校竟高达 1: 20, 大学教师每周授课量明显增 加, 由以前的 4-6 节, 增至现在的 20 节以上。尤其 是像广播电视编导、播音与主持艺术等艺术类招生专 业, 学生的招生规模远远超过专业教师的师资资源, 教学资源严重不足。办学规模扩大, 相应的教学设备 跟不上, 每一个学生所享受到的资源大打折扣, 从而 影响到教学质量。

\section{2. 最棘手恐怕还是就业难的问题}

一方面是教育规模扩大, 学生数量不断增加, 一 方面新闻传播人才的需求与人才培养模式脱节。这些 都无疑使新闻传播专业的学生就业竞争压力很大。近 年网上点击率很高的年度十大最难就业专业排名, 像 “广播电视编导” “新闻” 赫然在列。受到媒体发展 变革的影响，不少单位严格控制新闻采编人员的数 量。与此同时, 传统媒体向新媒体转型, 大量的纸媒 在市场竞争中被淘汰。这样就出现了新闻人才供求失 衡、学生就业难的问题。

\section{3. 传统的知识结构和教学模式不能适应新 媒体环境的变化}

新媒体的发展已经改变了当前新闻媒介的生态 环境, 传统媒体的布局发生了巨大变化。新闻传播教 育还有存在一个很严重的问题就是, 知识严重老化, 课程脱离实际。本科专业四年的课程量是不少, 但多 数学生仍然感到 “没有学到什么有用的东西”。还有 现象就是, 面对每年大量新闻传播类专业毕业生, 不 少新闻业界人士却感慨新闻传播人才的缺乏。就业难 最根本的原因不是人才饱和, 而是高校培养出来的学 生不符合社会的需要。正如很多毕业生描述的 “工作 不难找, 好工作难找”。

\section{3. 我国地方高校新闻传播教育的发展策略}

\section{1. 准确定位, 突出特色, 培养全媒体应用型 1才}

结合校情, 要有准确的市场定位, 制定初适合自 身发展的人才培养计划, 突出特色突出个性, 培养出 有市场竞争力的人才。尤其一般的本专科院校, 不能 盲目追求研究性大学、一流大学, 而是结合自身实际, 走坚实可行的实用型道路, 根据社会需求制定人才计 划。在科研实力不及重点大学的情况下, 发挥自身的 地方优势, 推行特色办学, 从提高学生就业率入手, 满足地方新闻媒体日益增长的人才需求, 占领中低层 市场。

高校新闻人才培养改革要倾听业界人士的意见, 及时做出判断, 制定出科学合理的人才培养计划。根 据媒体需要培养人才, 这样培养出来的学生才有市场 竞争力, 才能走入社会岗位后更加胜任。高校应该根 据新闻媒介的发展变化制定人才培养战略, 培养出适 应社会实际的应用型人才。

\section{2. 加强师资队伍建设, 建设一支学术水准 高、实践能力强的专业型队伍}

针对我国目前新闻教师队伍存在的学历水平参 差不齐、知识结构不理想、理论与实际脱节等问题, 我们应该在引进学历较高、富有活力的年轻教师到新 闻教学岗位的同时, 着力吸引一批富有新闻实践经验 的新闻人才充实到新闻教育队伍中来。新闻教育的实 践性很强, 高学历不一定能教好专业课程, 最重要的 是理论与实践相结合, 这就离不开丰富的新闻实践经 验。作为新闻传播类专业的教师, 除了要具备系统的 新闻理论知识和政策水平以及丰富的多学科知识以 外，也需要有较高的媒介素养和丰富的新闻实践经 验。新闻教师队伍中需要有来自新闻一线的编辑、记 者, 教研室主任、系主任中需要有总编辑、社长。但 目前高校新闻专业教师中这类人才非常少，而本校培 养的学生留校后当教师的近亲繁殖现象比较流行, 这 就容易形成纯理论教育与理论脱离实际的弊病, 使得 
培养出来的学生实际操作能力差, 很难胜任媒体工作 的要求。与媒体形成互动, 加强与新闻媒体的合作, 充分利用社会资源加强学生的实践能力的培养, 实现 教学与市场的接轨。很多高校建立了由新闻记者、广 告人从业背景的在编教师队伍, 和由业内一线学者型 记者和资深广告人为主的外聘教师队伍, 培养出一批 批能够适应市场竞争有创新思维和开拓能力的应用 型人才, 使学生在毕业就业前就能实现由学生到专业 新闻人的角色转变的。

\section{3. 更新教学理念, 建立应用型、实践型教学 体系}

新媒体时代, 新闻传播教育的理念应该引导学生 关注新媒体生态的变化, 探索如何做新媒体环境下的 媒介从业者。[5]教学课程设置要注重应用性、实践 性, 根据新闻媒体的从业人员知识、能力的实际需要, 培养学生合理的知识结构、拓宽学生的专业知识面, 提高学生的实际运用能力。当前大多数新闻单位都是 事业单位企业化管理，经济效益对新闻媒体来说被放 在了和社会效益同样重要的位置。这就需要新闻人才 文武双全, 既能用好中文, 又会运用外语; 既能写文 章, 又能捕捉信息; 操作电脑、摄影报道、组版印刷、 广告经营等都在所必行。富有多种知识技能的复合型 新闻人才成了新闻媒体青睐的宠儿, 因此, 新闻教育 在内容上就不能只偏重于新闻理论和新闻写作的教 学, 而是要重视多方面知识和多方面独立工作能力的 培养。

新闻传播类专业的的课程设置要加强人文综合 知识的融合, 同时要避免给学生灌输的东西太多太杂 乱, 这容易使学生到用人岗位上后出现似懂非懂, 知 识准备不足的窘境。推行课程体系创新十分必要, 使 这些知识能系统有序地组合在课程结构里, 形成完整 系统的知识基础。

推行课程体系创新, 从教学计划到课程实施都要 符合人才发展战略的理念，建议采取以下措施:

首先, 修订教学计划, 提供开设文学、哲学、社 会学、经济、法律等相关基础课程, 增加选修课的数 量, 开放所有的课程, 可以供学生跨系跨专业自由选 修, 给学生创造更多选择的机会。

其次, 定期举办讲座, 开设人文论坛, 追踪前沿 信息。邀请知名记者、学术权威人士走进校园, 献身 说法, 分析媒介最新态势。

最后, 完善评价体系, 把课堂教学和课外实践的 成果, 都计入学生成绩, 调动学生参加课外实践的积 极性。改变考试内容, 避免多是考死题、考记忆题的 现象, 增加操作性、实践性的考核。

\section{4. 完善人才培养方案, 注重培养学生的动 手能力}

新闻传播教育的目标在于为学生 “造”一份工作, 而非 “找”一份工作。[6]把动手能力的培养贯穿到 整个教学活动各个环节当中, 把培养学生的专业实践 贯穿到大学四年学习的每一个阶段当中。现代新闻传 播活动的发展要求专业新闻传播者具备极强的独立 作战能力。中国的新闻传媒已经逐步抛弃了 “一窝 峰”、“大呼隆”式的工作方式, 要求记者具备独立 工作的能力。教学与实践紧密结合, 合理安排教学活 动和实践活动。增加相关课程的实践环节, 除课堂讲 授之外, 应保留相应的课堂时间用于实践, 提高实践 环节的学分。从封闭式教学走向开放式教学, 把课堂 教学变为新闻实践的实习阵地, 让学生在实践中验证 理论, 在实践中理解与运用理论, 从而不断获得实际 思维能力和组织能力的提高。建立实用为主的人才培 养方案, 专业课程充分采用案例法、任务驱动、角色 设计、实战运营等多种教学方法, 实践教学让学生走 出课堂、走进新闻现场, 构建全新的融媒体新闻采编 实战环境。

目前集中短时间的实践活动是远远不够的，除了 交叉性安排教学和实习的时间, 还要广泛接触社会和 请社会各方面人士来补充和扩大课堂教学的信息量, 使学生在校期间就能不脱离生动丰富、多彩变幻的社 会生活的实践。因此，建议新闻专业教学要增加实习 时间, 多给学生创造动手实践的机会, 理论和实践并 重。建立教学实习基地, 推动学生实践能力的培养和 提高。在办学过程中, 依靠地方媒体的力量和优势, 在新闻媒体中建立固定的实习基地, 利用媒体的力量 对学生进行实践培训。

\section{4. 结语}

总的来说，智能媒体时代，地方院校新闻传播人 才的培养应该与时俱进、紧密结合行业需求, 注重人 文思想与传播技术的融合，既强调扎实的人文基础， 又重视现代传播技术的应用，用新技术表现深遂的人 文思想，以培养兼具思想性、艺术性、技术性的知识 和技能为一体的复合型 “新文科” 人才为目标。构建 实践教学平台, 充分利用网络与新媒体技术建立内容 创意与生产的融媒体实战环境; 修订新闻传播类专业 人才培养方案, 建立和业界接轨的实用型实践教学体 系; 更新教学理念, 实现课堂创新, 将新闻传媒行业 的需求渗透到课堂教学中; 地方院校应该和新闻媒 体、技术公司、高水平大学形成良好互动, 通过实习 基地建设和人才互派计划, 探索产学研协同育人模 式。推进实验室在机构、渠道、平台、人员、教学等 方面深度融合, 建立新闻传播实践教学基地, 成为学 校的主流與论阵地、與情聚合平台、校园服务平台、 学生实践平台。实践教学模式模拟业务的产出, 为学 生提供策划、采编发运营的实战条件，为学生思维训 练和创新实践提供开放空间, 把教学成果直接体现在 
学生的专业创新上, 激励学生完成与新闻媒体、数字 出版业界紧密联系的创新实践。

\section{REFERENCES}

[1] China Internet Network Information Center.(2020)Statistical Report on the development of Internet in China.

[2] Ministry of Education of the People's Republic of China.(2018)http://www.moe.gov.cn/srcsite/A08/s 7056/201810/t20181017_351893.html

[3] Research Committee on the history of journalism and Communication Education of the Chinese Society for the history of journalism. (2018)Yearbook of journalism and Communication
Education in China(2018).Wuhan University press, Wuhan.19-21.

[4] Wang, Z.P.(2014)China's journalism and communication education:Constraints and possible breakthrough.Modern Communication(Journal of Communication University of China), 36(10):135-139.

[5] Yu,X.C. (2015)The dilemma and innovation of News Communication Education in the context of new media.University of Journalism,(04):133-139

[6] Li, J.X. (2015)New Changes and new countermeasures of News Communication Education. University of Journalism,(03):141-145. 